\title{
A Review on the Relationship between SGLT2 Inhibitors and Cancer
}

\author{
Hao-Wen Lin ${ }^{1}$ and Chin-Hsiao Tseng ${ }^{2}$ \\ ${ }^{1}$ Division of Endocrinology and Metabolism, Department of Internal Medicine, National Taiwan University Hospital, \\ Yun-Lin Branch, Yunlin, Taiwan \\ ${ }^{2}$ Division of Endocrinology and Metabolism, Department of Internal Medicine, National Taiwan University Hospital, \\ No. 7 Chung-Shan South Road, Taipei 10002, Taiwan
}

Correspondence should be addressed to Chin-Hsiao Tseng; ccktsh@ms6.hinet.net

Received 5 August 2014; Accepted 20 August 2014; Published 31 August 2014

Academic Editor: Ilias Migdalis

Copyright (C) 2014 H.-W. Lin and C.-H. Tseng. This is an open access article distributed under the Creative Commons Attribution License, which permits unrestricted use, distribution, and reproduction in any medium, provided the original work is properly cited.

Risk of increasing breast and bladder cancer remains a safety issue of SGLT2 (sodium glucose cotransporter type 2) inhibitors, a novel class of antidiabetic agent. We reviewed related papers published before January 29, 2014, through Pubmed search. Dapagliflozin and canagliflozin are the first two approved SGLT2 inhibitors for diabetes therapy. Although preclinical animal toxicology did not suggest a cancer risk of dapagliflozin and overall tumor did not increase, excess numbers of female breast cancer and male bladder cancer were noted in preclinical trials (without statistical significance). This concern of cancer risk hindered its approval by the US FDA in January, 2012. New clinical data suggested that the imbalance of bladder and breast cancer might be due to early diagnosis rather than a real increase of cancer incidence. No increased risk of overall bladder or breast cancer was noted for canagliflozin. Therefore, the imbalance observed with dapagliflozin treatment should not be considered as a class effect of SGLT2 inhibitors and the relationship with cancer for each specific SGLT2 inhibitor should be examined individually. Relationship between SGLT2 inhibition and cancer formation is still inconclusive and studies with larger sample size, longer exposure duration, and different ethnicities are warranted.

\section{Introduction}

The prevalence of type 2 diabetes mellitus is increasing globally with time $[1,2]$. According to an epidemiological study with 370 country years and 2.7 million participants, prevalence of diabetes in adults aged 25 years and older was $9.8 \%$ in men and 9.2\% in women in 2008, leading to an estimated 173 million men and 173 million women with diabetes [1]. Intensive glycemic control was associated with significantly decreased rates of microvascular and neuropathic complications in type 2 diabetic patients [3, 4]. More intensive glycemic control in newly diagnosed type 2 diabetic patients may reduce long-term cardiovascular disease rates [5]. Along with lifestyle modification, medications with different mechanisms may be needed to achieve glycemic goal.

SGLT2 (sodium glucose cotransporter type 2) inhibitor is a novel class of antidiabetic agent acting independent of effects on insulin resistance or insulin insufficiency. Glucose filtered through the kidneys is reabsorbed into the blood in the proximal tubules via SGLT1 and SGLT2 [6]. SGLT2 accounts for $90 \%$ and SGLT1 accounts for $10 \%$ of the glucose reabsorbed from the kidneys $[7,8]$. SGLT2 is expressed mainly in the kidney cortex [9]. Beside the kidney, SGLT1 is mainly expressed in small intestine and also in trachea, heart, and plasma membranes $[6,9]$. Blocking these transporters in the kidney inhibits renal glucose reabsorption and may lower blood glucose levels in diabetic patients. However, nonselective inhibition of SGLT1 and SGLT2 can cause severe diarrhea $[10,11]$. Oral agents with high selectivity of SGLT2 have been developed to overcome the shortcoming [11]. Use of selective SGLT2 inhibitors significantly lowers HbAlc levels by $0.5-1.5 \%$ without hypoglycemia [12-17]. Use of SGLT inhibitors also showed significant weight loss and reduction of systemic blood pressure [13, 14, 16-18]. Increased genital 
TABLE 1: SGLT2 inhibitors under phase II and phase III clinical trials.

\begin{tabular}{|c|c|c|}
\hline Drug & Company & Phase of clinical trial \\
\hline $\begin{array}{l}\text { Dapagliflozin } \\
\text { (BMS-512148) }\end{array}$ & Bristol-Myers Squibb/AstraZeneca & $\begin{array}{l}\text { Phase III (approved in Australia (Oct 2012), Europe (Nov 2012), } \\
\text { Mexico (Mar 2013), New Zealand (June 2013), Brazil (July 2013), } \\
\text { Argentina (Sep 2013), US (Jan 2014), and Japan (Mar 2014)) }\end{array}$ \\
\hline $\begin{array}{l}\text { Canagliflozin (TA-7284, } \\
\text { JAJ-28431754) } \\
\end{array}$ & $\begin{array}{l}\text { Johnson and Johnson and } \\
\text { Mitsubishi Tanabe Pharma }\end{array}$ & Phase III (approved in US (Mar 2013) and Europe (Nov 2013)) \\
\hline Empagliflozin (BI-10773) & Boehringer Ingelheim/Lilly & Phase III (approved in Europe (May 2014)) \\
\hline Ipragliflozin (ASP-1941) & $\begin{array}{l}\text { Astellas Pharma and Kotobuki } \\
\text { Pharmaceutical Company }\end{array}$ & Phase III (approved in Japan (Jan 2014) \\
\hline Tofogliflozin (CSG452) & Roche/Chugai & Phase III \\
\hline Luseogliflozin (TS-071) & Taisho & Phase III \\
\hline BI 44847 & Boehringer Ingelheim & Phase III \\
\hline LX4211 & Lexicon Pharmaceutical & Phase II \\
\hline PF-04971729 & Pfizer & Phase II \\
\hline EGT0001442 & Theracos & Phase II \\
\hline GW 869682 & GlaxoSmithKline & Phase II \\
\hline
\end{tabular}

From $[17,19]$.

infection and possibly increased urinary tract infection were noticed but rarely caused drug discontinuation $[7,11,16,17$, 19].

Currently, more than ten SGLT2 inhibitors are under development $[17,19]$. SGLT2 inhibitors under phase II and III clinical trials are listed in Table 1. Dapagliflozin was the first SGLT2 inhibitor approved in the world. It was approved in Europe in November 2012 and in USA in January 2014. Dapagliflozin should be given at an initial dose of $5 \mathrm{mg}$ per day and may be increased to $10 \mathrm{mg}$ per day and it is not recommended in patients with limited renal function (eGFR $<60 \mathrm{~mL} /$ minute $/ 1.73 \mathrm{~m}^{2}$ ) [20]. Canagliflozin was approved in Europe and in USA in 2013. It should be given at an initial dose of $100 \mathrm{mg}$ per day and may be increased to $300 \mathrm{mg}$ per day in a once daily dose. Canagliflozin was not recommended in patients with severe renal impairment and end stage renal disease [14].

Patients with diabetes are at an increased risk of bladder cancer compared with those without diabetes [21-26]. Use of some antidiabetic agents (e.g., pioglitazone) might be associated with increased risk of bladder cancer [27-33] and some (e.g., metformin) were associated with lower risk [34]. An imbalance of male bladder cancer and female breast cancer was observed in the treatment arms of dapagliflozin [35]. This ever hindered the approval of dapagliflozin by the FDA in January, 2012. Therefore, it is important to clarify the cancer risk associated with the use of SGLT2.

Publications before January 29, 2014, were searched in the Pubmed using key words including "SGLT1 and cancer," "SGLT2 and cancer," "canagliflozin and cancer," "dapagliflozin and cancer," "empagliflozin and cancer," "ipragliflozin and cancer," "tofogliflozin and cancer," "luseogliflozin and cancer," and "BI 44847 and cancer." Except for the two approved SGLT2 inhibitors (i.e., dapagliflozin and canagliflozin), the incidence of cancer for the other SGLT2 inhibitors was not available. Hence, the present review will focus on the cancer risk associated with dapagliflozin and canagliflozin.

\section{Dapagliflozin}

Among phase $2 \mathrm{~b}$ and phase 3 trials presented to FDA in 2011, event rates for male bladder cancer and female breast cancer in the active treatment arms of dapagliflozin exceeded the rates expected in an age-matched reference of diabetic population [35]. However, the imbalance was not statistically significant.

More updated data until November, 2013, were gathered through 21 phase $2 \mathrm{~b}$ and phase 3 trials [20]. The incidence rate ratios of malignancy by tumor type compared to dapagliflozin and nondapagliflozin groups were listed in Table 2. There was no overall imbalance of malignancies [20]. Though not significant, some tumor types (such as bladder cancer and female breast cancer) were more common while others (such as renal tract cancer) were less common in the dapagliflozin group.

2.1. Bladder Cancer. At the time of the FDA advisory committee meeting in 2011, 9 cases of bladder cancer were reported on dapagliflozin out of 5,478 patients and one was reported on control out of 3,156 patients among 14 phase $2 \mathrm{~b}$ and 3 clinical trials [35].

Updated data presented in November, 2013, were gathered from 21 phase $2 \mathrm{~b}$ and 3 clinical trials of dapagliflozin. With 2000 additional patient-years of exposure compared to those in 2011, no additional case of bladder cancer was identified. All previously detected cases of bladder cancer were males. Subsequent follow-up after the integrated database was locked, a new case of bladder cancer was reported in a female patient who participated in an ongoing add-on sulfonylurea and metformin study [20]. This additional female patient of bladder cancer was a smoker who had hematuria at baseline, and the bladder cancer was diagnosed only 3.5 months after initiation of treatment [20].

Till November, 2013, a total of 10 cases of bladder cancer out of 6,045 patients $(0.17 \%)$ were noted in the dapagliflozin 
TABLE 2: Incidence rate ratio of malignancy by tumor type comparing dapagliflozin versus nondapagliflozin in 21 phase $2 \mathrm{~b}$ and phase 3 clinical trials (dapagliflozin $N=5936$ and control $N=3403$ ).

\begin{tabular}{lccc}
\hline Tumor origin & Patients with events & Incidence rate ratio & 95\% confidence interval \\
\hline Overall & 140 & 1.03 & $0.71,1.51$ \\
Bladder & 10 & 5.17 & $0.68,233.55$ \\
Breast (female only) & 15 & 2.47 & $0.64,14.10$ \\
Pancreas & 8 & 1.84 & $0.31,19.46$ \\
Prostate (male only) & 17 & 1.50 & $0.53,5.35$ \\
Hepatobiliary & 3 & 0.92 & $0.04,61.49$ \\
Thyroid and endocrine & 10 & 0.88 & $0.19,4.46$ \\
Skin & 31 & 0.83 & $0.37,1.91$ \\
Respiratory and mediastinal & 15 & 0.79 & $0.24,2.81$ \\
Female reproductive (female only) & 4 & 0.74 & $0.05,10.74$ \\
Metastases and site unspecified & 5 & 0.56 & $0.07,8.96$ \\
Gastrointestinal & 10 & 0.51 & $0.13,3.19$ \\
Renal tract & 5 & 0.40 & $0.03,3.82$ \\
Blood/lymphatic & 7 & 0.37 & $0.05,2.35$ \\
Musculoskeletal and soft tissue & 1 & $\infty$ & $0.010, \infty$ \\
\hline
\end{tabular}

Source: reference [20,35]: data obtained from 21 phase $2 \mathrm{~b}$ and 3 clinical trials, data cutoff date: Nov 4, 2013; a new case of bladder cancer found in an ongoing add-on to sulfonylurea and metformin phase 3 trial is not included. The incidence rate ratio with $95 \% \mathrm{CI}$ including the case is $6.11(0.827-272.00)$.

treatment group compared to 1 case of bladder cancer out of 3,512 patients $(0.03 \%)$ in the placebo arms [20]. All 10 cases of bladder cancer were reported within 2 years of starting dapagliflozin. All but one showed hematuria, which was the first clinical sign of bladder cancer, within 6 months of starting treatment [20]. The incidence rate remained stable over the first 2 years of drug exposure then fell, with no additional case detected between 2-4 years of exposure. The characteristics of bladder cancer differed from low grade to high grade and from noninvasive to widely metastatic [20]. The biological heterogeneity argued against a single triggering cause for the cancer [20].

A recently published study by Reilly et al. disclosed that, in mice and rats, exposure to dapagliflozin for up to 2 years at greater than a 100-fold human clinical exposure did not increase tumor incidence or urinary bladder proliferative/preneoplastic lesions [36]. In their study, dapagliflozin and its primary metabolite did not affect in vitro transitional cell carcinoma (TCC) proliferation rates and dapagliflozin did not enhance tumor growth in nude mice heterotopically implanted with human bladder TCC cell lines [36].

Therefore, the clinical observation of imbalance in bladder cancer associated with dapagliflozin was not supported by animal or in vitro studies, and the early diagnosis of bladder cancer might be due to detection bias rather than true causal relationship.

2.2. Breast Cancer. In an animal carcinogenicity study, dapagliflozin was administered to Sprague-Dawley rats up to 186fold human exposure for 90 weeks in males and 105 weeks in females [36]. No mammary tumor was noted in the male rats during study. In the female rats, the most common causes of death in treatment and control groups were benign and malignant mammary and pituitary tumors. However, there was no dapagliflozin related increase in the incidence of these tumors and there was no difference in the time to onset of the tumors [36].

In the data presented in the FDA advisory committee meeting in 2011, 9 cases of breast cancer out of 2,223 female patients $(0.4 \%)$ were noted in the dapagliflozin treatment group compared to 1 case out of 1,053 female patients $(0.09 \%)$ in the placebo group $[35,37]$.

Till November, 2013, the total number of breast cancer cases on dapagliflozin was 12 and was 3 for the control group [20]. Exposure adjusted incidence rate was 0.40 per 100 patient-years $(95 \% \mathrm{CI}=0.21,0.70)$ on dapagliflozin and 0.19 $(95 \% \mathrm{CI}=0.04,0.56)$ in the control group [20]. The incidence rate ratio decreased from $4.41(95 \% \mathrm{CI}=0.57,200.86)$ as estimated in 2011 to $2.47(95 \% \mathrm{CI}=0.64,14.10)$ in 2013 when more patient exposure was included [20].

All female breast cancers were diagnosed within the first year of treatment and were heterogeneous in patient age, tumor type, stage, progesterone/estrogen receptor status, and HER2/neu status [20]. These may not support a causative role for dapagliflozin.

\section{Canagliflozin}

In an animal study, lifetime exposure to canagliflozin in CD1 mice at doses up to a 14-fold human clinical exposure did not increase the incidence of neoplasms or preneoplastic histological lesions [14].

Canagliflozin was associated with increased neoplasms of renal tubules, adrenals, and testicular Leydig cells (LCT) in Sprague-Dawley rats, which were preceded by carbohydrate malabsorption and disrupted calcium homeostasis [14, 38, 39]. However, canagliflozin does not result in significant carbohydrate malabsorption or calcium imbalance in humans [14]. 
TABLE 3: Incidence rates of bladder and breast cancer with canagliflozin exposure.

\begin{tabular}{llcc}
\hline Canagliflozin & $N$ & $\begin{array}{c}\text { Subjects with } \\
\text { events (\%) }\end{array}$ & $\begin{array}{c}\text { Rate per 1000 } \\
\text { patient-year }\end{array}$ \\
\hline Canagliflozin 100 mg & 3139 & $2(0.06)$ & 0.44 \\
Canagliflozin 300 mg & 3506 & $3(0.09)$ & 0.63 \\
All canagliflozin & 6645 & $5(0.07)$ & \\
All noncanagliflozin & 3640 & $4(0.11)$ & 0.84 \\
\hline & \multicolumn{3}{c}{ Breast Cancer } \\
Canagliflozin 100 mg & 1313 & $5(0.38)$ & 2.61 \\
Canagliflozin 300 mg & 1514 & $7(0.46)$ & 3.39 \\
All canagliflozin & 2827 & $12(0.42)$ & \\
All noncanagliflozin & 1501 & $6(0.4)$ & 3.05 \\
\hline
\end{tabular}

Source: reference [14], data obtained from 8 phase 3 clinical trials, data cutoff date: Nov 15, 2012.

Due to the increased renal, adrenal, and LCT tumor associated with canagliflozin in rat studies and the clinical imbalance of bladder and breast cancer associated with dapagliflozin, the incidence of these five cancers was followed through 8 phase 3 trials with canagliflozin. There were 6,645 patients who underwent canagliflozin and 3,640 patients who underwent noncanagliflozin treatment.

Till November 15, 2012, there were no reported cases of pheochromocytoma or malignant adrenal tumors in the treatment group [14]. One case of testicular cancer was reported 2 months after starting canagliflozin $100 \mathrm{mg}$. The patient had an enlarged scrotum a year prior to trial entry and had scrotal pain before trial entry. The prior scrotal abnormality and the short latency period did not support a drug-related causality [14].

The overall incidence of bladder, breast, and renal cancers did not increase in canagliflozin treatment groups while being compared to the noncanagliflozin groups (Table 3) [14, 37].

\section{Discussion}

4.1. Class Effect of Cancer Risk Unlikely for SGLT2 Inhibitors. Statistical data did not reveal an overall imbalance of cancer in both canagliflozin and dapagliflozin [14, 20, 35]. An increased incidence of bladder cancer without statistical significance was observed in patients treated with dapagliflozin. However, this was not similarly observed in patients treated with canagliflozin, which actually showed a trend of decreased risk (Table 3 ). Therefore, the risk of bladder cancer associated with SGLT2 inhibitors is not conclusive and such a risk is unlikely a class effect.

\subsection{Cancer Risk Not Increased in SGLT2 Knockout Animals.} Reilly et al. studied the potential carcinogenic risk of inhibiting SGLT2 in SGLT2 ${ }^{-/-}$mice [36]. The 15 -month study included 36 (23 male and 13 female) SGLT knockout mice and 33 (16 male, 17 female) wild type mice. At 15 months, $86 \%$ of knockout mice and $85 \%$ wild type mice survived.
Knockout mice exhibited substantial glucosuria. Microscopic evaluation of urinary bladder, kidneys, liver, heart, pancreas, adrenal glands, thyroids, spleen, female reproductive tract, male sex glands, skin, brain, and skull did not reveal adverse effect of SGLT2 gene deletion. Neither hyperplasia nor neoplasia was observed in the urinary bladder mucosa, urogenital tract, or kidneys of SGLT2 knockout mice [36].

4.3. Cancer Cells May Overexpress SGLT. In humans, SGLT1 is overexpressed in many cancers $[19,40]$. Inhibition of SGLT1 sensitizes prostate cancer cells to treatment with EGFR (epidermal growth factor receptor) tyrosine kinase inhibitor [40]. High SGLT1 level combined with high MAP17 (membrane-associated protein 17) is a marker for good prognosis in patients with cervical cancer after chemotherapy and radiotherapy [41]. High SGLT1 expression in pancreatic adenocarcinomas was significantly correlated with disease free survival, especially in younger patients [42]. On the other side, overexpression of SGLT1 is related to tumor development and poor prognosis of ovarian carcinoma [43]. In oral squamous cell carcinoma, SGLT1/EGFR expression was inversely related to tumor differentiation [44]. SGLT1/EGFR overexpression in colorectal cancer was related to higher clinical stages though SGLT1 expression was not associated with the prognosis [45].

In a study of lung cancer, there were no significant differences in the level of SGLT1 or SGLT2 gene expression between the primary lung cancers and the normal lung tissues [46]. However, higher SGLT2 expression was found in metastatic lesions of lung cancer compared to primary tumor [46].

Studies above imply that SGLT, especially SGLT1, plays a role in glucose uptake in many cancers. From this point of view, inhibition of SGLT1 and SGLT2 might even be protective in certain cancer types. If there was any positive link between dapagliflozin and bladder cancer, mechanisms other than inhibition of SGLT2 should be considered. Again, relationship between different SGLT2 inhibitors and bladder cancer should be examined individually.

\subsection{Detection Bias and Increased Bladder Cancer Risk Induced} by Glucosuria and Urinary Tract Infection Related to SGLT2 Use. SGLT2 inhibitors block renal glucose reabsorption resulting in increased glucosuria. Increased urinary tract and genital infections were observed in patients treated with SGLT2 inhibitors [7, 8, 15-17, 19]. The increased use of urinalysis in these patients may lead to a detection bias for bladder cancer. However, the possibility of an increased risk of bladder cancer induced by chronic glucosuria and urinary tract infection among patients who use SGLT2 inhibitors cannot be excluded.

In SGLT2 ${ }^{-/-}$mice, lifelong glucosuria did not increase the incidence of bladder tumor [36]. However, patients with diabetes are indeed at an increased risk of bladder cancer compared with those without diabetes [21-26]. Recurrent or chronic urinary tract infection may cause chronic irritation to bladder epithelium and is a potential risk factor of bladder cancer in humans [47-50]. The duration of current human studies on SGLT2 inhibitors is probably not long enough to 
answer the question and careful postmarketing surveillance should be conducted.

4.5. Ethnicity and Sexual Differences. Ethnicity should be taken into consideration while evaluating the risk of bladder cancer. Diabetes associated bladder cancer risk was obviously higher in Asia populations [21]. A population-based matched case-control study performed in the USA, suggested a reduced risk of bladder cancer in women, but not in men, with a history of urinary tract infection [51]. However, a large population-based study in Taiwan disclosed that urinary tract infection is significantly associated with increased bladder cancer risk in both sexes [25].

In phase $2 \mathrm{~b}$ and phase 3 studies of dapagliflozin presented to the FDA, Asian ethnicities account for less than $20 \%$ of the study population [20]. The sample size of the studied Asian population was probably too small to evaluate the effect in this specific ethnic group of patients.

\section{Conclusions}

Molecular evidences and animal studies do not suggest a positive link between exposure to SGLT2 inhibitors and cancer risk. The imbalance of bladder cancer and breast cancer with dapagliflozin treatment in humans could be a result of early diagnosis of preexisting cancer. However, longterm effects should be examined carefully by including larger sample size, with longer exposure duration, and in different ethnicities.

\section{Conflict of Interests}

The authors declare that there is no conflict of interests regarding the publication of this paper.

\section{Acknowledgments}

The authors thank the National Science Council (NSC1022314-B-002-067) of Taiwan for continuous support on epidemiological studies on diabetes and arsenic-related health issues. The publication fee of this paper is supported by the Weng Yuan Endocrine Fund.

\section{References}

[1] G. Danaei, M. M. Finucane, Y. Lu et al., "National, regional, and global trends in fasting plasma glucose and diabetes prevalence since 1980: systematic analysis of health examination surveys and epidemiological studies with 370 country-years and 2.7 million participants," The Lancet, vol. 378, no. 9785, pp. 31-40, 2011.

[2] S. Wild, G. Roglic, A. Green, R. Sicree, and H. King, "Global prevalence of diabetes: estimates for the year 2000 and projections for 2030," Diabetes Care, vol. 27, no. 5, pp. 1047-1053, 2004.

[3] Y. Ohkubo, H. Kishikawa, E. Araki et al., "Intensive insulin therapy prevents the progression of diabetic microvascular complications in Japanese patients with non-insulin-dependent diabetes mellitus: a randomized prospective 6-year study,"
Diabetes Research and Clinical Practice, vol. 28, no. 2, pp. $103-$ 117, 1995.

[4] UK Prospective Diabetes Study (UKPDS) Group, "Intensive blood-glucose control with sulphonylureas or insulin compared with conventional treatment and risk of complications in patients with type 2 diabetes (UKPDS 33)," The Lancet, vol. 352, no. 9131, pp. 837-853, 1998.

[5] R. R. Holman, S. K. Paul, M. A. Bethel, D. R. Matthews, and H. A. W. Neil, "10-Year follow-up of intensive glucose control in type 2 diabetes," New England Journal of Medicine, vol. 359, no. 15, pp. 1577-1589, 2008.

[6] E. M. Wright, "Renal Na(+)-glucose cotransporters," American Journal of Physiology - Renal Physiology, vol. 280, no. 1, pp. F10F18, 2001.

[7] M. Bhartia, A. A. Tahrani, and A. H. Barnett, "SGLT-2 inhibitors in development for type 2 diabetes treatment," Review of Diabetic Studies, vol. 8, no. 3, pp. 348-354, 2011.

[8] E. Ferrannini and A. Solini, "SGLT2 inhibition in diabetes mellitus: rationale and clinical prospects," Nature Reviews Endocrinology, vol. 8, no. 8, pp. 495-502, 2012.

[9] E. M. Wright and E. Turk, "The sodium/glucose cotransport family SLC5," Pflugers Archiv, vol. 447, no. 5, pp. 510-518, 2004.

[10] J. R. L. Ehrenkranz, N. G. Lewis, C. R. Kahn, and J. Roth, "Phlorizin: a review," Diabetes/Metabolism Research and Reviews, vol. 21, no. 1, pp. 31-38, 2005.

[11] J. E. Gerich and A. Bastien, "Development of the sodiumglucose co-transporter 2 inhibitor dapagliflozin for the treatment of patients with Type 2 diabetes mellitus," Expert Review of Clinical Pharmacology, vol. 4, no. 6, pp. 669-683, 2011.

[12] J. Rosenstock, N. Aggarwal, D. Polidori et al., "Dose-ranging effects of canagliflozin, a sodium-glucose cotransporter 2 inhibitor, as add-on to metformin in subjects with type 2 diabetes," Diabetes Care, vol. 35, no. 6, pp. 1232-1238, 2012.

[13] S. A. Nisly, D. M. Kolanczyk, and A. M. Walton, "Canagliflozin, a new sodium-glucose cotransporter 2 inhibitor, in the treatment of diabetes," The American Journal of Health-System Pharmacy, vol. 70, no. 4, pp. 311-319, 2013.

[14] U.S. Food and Drug Administration, "FDA Briefing Document, NDA 204042 Canagliflozin tablets. Advisory Committee Meeting: 2013," http://www.fda.gov/downloads/AdvisoryCommittees/CommitteesMeetingMaterials/Drugs/EndocrinologicandMetabolicDrugsAdvisoryCommittee/UCM334550.pdf.

[15] E. Ferrannini, A. Berk, S. Hantel et al., "Long-term safety and efficacy of empagliflozin, sitagliptin , and metformin: an activecontrolled, parallel-group, randomized, 78-week open-label extension study in patients with type 2 diabetes," Diabetes Care, vol. 36, no. 12, pp. 4015-4021, 2013.

[16] J. Rosenstock, L. J. Seman, A. Jelaska et al., "Efficacy and safety of empagliflozin, a sodium glucose cotransporter 2 (SGLT2) inhibitor, as add-on to metformin in type 2 diabetes with mild hyperglycaemia," Diabetes, Obesity and Metabolism, vol. 15, no. 12, pp. 1154-1160, 2013.

[17] R. F. Rosenwasser, S. Sultan, D. Sutton, R. Choksi, and B. J. Epstein, "SGLT-2 inhibitors and their potential in the treatment of diabetes," Journal of Diabetes, Metabolic Syndrome and Obesity, vol. 6, pp. 453-467, 2013.

[18] N. Inagaki, K. Kondo, T. Yoshinari, N. Maruyama, Y. Susuta, and H. Kuki, "Efficacy and safety of canagliflozin in Japanese patients with type 2 diabetes: a randomized, double-blind, placebo-controlled, 12-week study," Diabetes, Obesity and Metabolism, vol. 15, no. 12, pp. 1136-1145, 2013. 
[19] S. Cangoz, Y. Y. Chang, S. J. Chempakaseril et al., "The kidney as a new target for antidiabetic drugs: SGLT2 inhibitors," Journal of Clinical Pharmacy and Therapeutics, vol. 38, no. 5, pp. 350-359, 2013.

[20] U.S. Food and Drug Administration, "FDA background document, BMS-512148 NDA 202293 dapagliflozin," in Proceedings of the Endocrinologic \& Metabolic Drug Advisory Committee Meeting, 2013, http://www.fda.gov/downloads/drugs/endocrinologicandmetabolicdrugsadvisorycommittee/ucm378079.pdf.

[21] X.-Q. Yang, C. Xu, Y. Sun, and R.-F. Han, "Diabetes mellitus increases the risk of bladder cancer: an updated meta-analysis," Asian Pacific Journal of Cancer Prevention, vol. 14, no. 4, pp. 2583-2589, 2013.

[22] H. Fang, B. Yao, Y. Yan et al., "Diabetes mellitus increases the risk of bladder cancer: an updated meta-analysis of observational studies," Diabetes Technology \& Therapeutics, vol. 15, no. 11, pp. 914-922, 2013.

[23] Z. Zhu, X. Wang, Z. Shen, Y. Lu, S. Zhong, and C. Xu, "Risk of bladder cancer in patients with diabetes mellitus: an updated meta-analysis of 36 observational studies," BMC Cancer, vol. 13, article 310, 2013.

[24] C.-H. Tseng, C.-K. Chong, C.-P. Tseng, and T.-T. Chan, "Agerelated risk of mortality from bladder cancer in diabetic patients: a 12-year follow-up of a national cohort in Taiwan," Annals of Medicine, vol. 41, no. 5, pp. 371-379, 2009.

[25] C.-H. Tseng, "Diabetes and risk of bladder cancer: a study using the National Health Insurance database in Taiwan," Diabetologia, vol. 54, no. 8, pp. 2009-2015, 2011.

[26] C.-H. Tseng, "Benign prostatic hyperplasia is a significant risk factor for bladder cancer in diabetic patients: a populationbased cohort study using the National Health Insurance in Taiwan," BMC Cancer, vol. 13, article 7, 2013.

[27] C.-H. Tseng, "Pioglitazone and bladder cancer: a populationbased study of Taiwanese," Diabetes Care, vol. 35, no. 2, pp. 278280, 2012.

[28] R. Mamtani, K. Haynes, W. B. Bilker et al., "Association between longer therapy with thiazolidinediones and risk of bladder cancer: a cohort study," Journal of the National Cancer Institute, vol. 104, no. 18, pp. 1411-1421, 2012.

[29] L. Azoulay, H. Yin, K. B. Filion et al., "The use of pioglitazone and the risk of bladder cancer in people with type 2 diabetes: nested case-control study," BMJ, vol. 344, Article ID e3645, 2012.

[30] L. Wei, T. M. Macdonald, and I. S. Mackenzie, "Pioglitazone and bladder cancer: a propensity score matched cohort study," British Journal of Clinical Pharmacology, vol. 75, no. 1, pp. 254259, 2013.

[31] C. H. Tseng, "A review on thiazolidinediones and bladder cancer in human studies," Journal of Environmental Science and Health C, vol. 32, no. 1, pp. 1-45, 2014.

[32] J. D. Lewis, A. Ferrara, T. Peng et al., "Risk of bladder cancer among diabetic patients treated with pioglitazone: interim report of a longitudinal cohort study," Diabetes Care, vol. 34, no. 4, pp. 916-922, 2011.

[33] A. Neumann, A. Weill, P. Ricordeau, J. P. Fagot, F. Alla, and H. Allemand, "Pioglitazone and risk of bladder cancer among diabetic patients in France: a population-based cohort study," Diabetologia, vol. 55, no. 7, pp. 1953-1962, 2012.

[34] C. H. Tseng, "Metformin may reduce bladder cancer risk in Taiwanese patients with type 2 diabetes," Acta Diabetol, vol. 51, no. 2, pp. 295-303, 2014.
[35] U.S. Food and Drug Administration, FDA Briefing Document, NDA 202293 Dapagliflozin tablets, 5 and $10 \mathrm{mg}$. Advisory Committee Meeting, 2011, http://www.fda.gov/downloads/advisorycommittees/committeesmeetingmaterials/drugs/endocrinologicandmetabolicdrugsadvisorycommittee/ucm262994.pdf.

[36] T. P. Reilly, M. J. Graziano, E. B. Janovitz et al., "Carcinogenicity risk assessment supports the chronic safety of dapagliflozin, an inhibitor of sodium-glucose co-transporter 2, in the treatment of type 2 diabetes mellitus," Diabetes Therapy, vol. 5, no. 1, pp. 73-96, 2014.

[37] D. Jones, "Diabetes field cautiously upbeat despite possible setback for leading SGLT2 inhibitor," Nature Reviews Drug Discovery, vol. 10, no. 9, pp. 645-646, 2011.

[38] D. E. Prentice and A. W. Meikle, "A review of drug-induced Leydig cell hyperplasia and neoplasia in the rat and some comparisons with man," Human and Experimental Toxicology, vol. 14, no. 7, pp. 562-572, 1995.

[39] F. J. C. Roe, "Relevance for man of the effects of lactose, polyols and other carbohydrates on calcium metabolism seen in rats: a review," Human Toxicology, vol. 8, no. 2, pp. 87-98, 1989.

[40] J. Ren, L. R. Bollu, F. Su et al., "EGFR-SGLT1 interaction does not respond to EGFR modulators, but inhibition of SGLT1 sensitizes prostate cancer cells to EGFR tyrosine kinase inhibitors," Prostate, vol. 73, no. 13, pp. 1453-1461, 2013.

[41] M. Perez, J. M. Praena-Fernandez, B. Felipe-Abrio et al., "MAP17 and SGLT1 protein expression levels as prognostic markers for cervical tumor patient survival," PLoS ONE, vol. 8, no. 2, Article ID e56169, 2013.

[42] V. F. Casneuf, P. Fonteyne, N. van Damme et al., "Expression of SGLT1, Bcl-2 and p53 in primary pancreatic cancer related to survival," Cancer Investigation, vol. 26, no. 8, pp. 852-859, 2008.

[43] B. Lai, Y. Xiao, H. Pu, Q. Cao, H. Jing, and X. Liu, "Overexpression of SGLT1 is correlated with tumor development and poor prognosis of ovarian carcinoma," Archives of Gynecology and Obstetrics, vol. 285, no. 5, pp. 1455-1461, 2012.

[44] Y. Hanabata, Y. Nakajima, K. I. Morita, K. Kayamori, and K. Omura, "Coexpression of SGLT1 and EGFR is associated with tumor differentiation in oral squamous cell carcinoma," Odontology, vol. 100, no. 2, pp. 156-163, 2012.

[45] G. F. Guo, Y. C. Cai, B. Zhang et al., "Overexpression of SGLT1 and EGFR in colorectal cancer showing a correlation with the prognosis," Medical Oncology, vol. 28, no. 1, pp. S197-S203, 2011.

[46] N. Ishikawa, T. Oguri, T. Isobe, K. Fujitaka, and N. Kohno, "SGLT gene expression in primary lung cancers and their metastatic lesions," Japanese Journal of Cancer Research, vol. 92, no. 8, pp. 874-879, 2001.

[47] C. Pelucchi, C. Bosetti, E. Negri, M. Malvezzi, and C. La Vecchia, "Mechanisms of disease: the epidemiology of bladder cancer," Nature Clinical Practice Urology, vol. 3, no. 6, pp. 327-340, 2006.

[48] S. Janković and V. Radosavljević, "Risk factors for bladder cancer," Tumori, vol. 93, no. 1, pp. 4-12, 2007.

[49] R. L. Jacobs, C. T. Lee, and J. E. Montie, "Bladder cancer in 2010 how far have we come?" CA Cancer Journal for Clinicians, vol. 60, no. 4, pp. 244-272, 2010.

[50] D. Volanis, T. Kadiyska, A. Galanis, D. Delakas, S. Logotheti, and V. Zoumpourlis, "Environmental factors and genetic susceptibility promote urinary bladder cancer," Toxicology Letters, vol. 193, no. 2, pp. 131-137, 2010.

[51] X. Jiang, J. E. Castelao, S. Groshen et al., "Urinary tract infections and reduced risk of bladder cancer in Los Angeles," British Journal of Cancer, vol. 100, no. 5, pp. 834-839, 2009. 


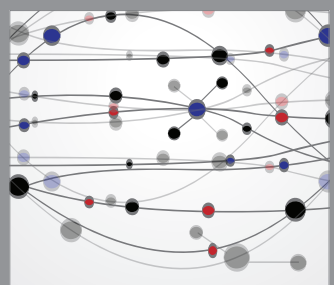

The Scientific World Journal
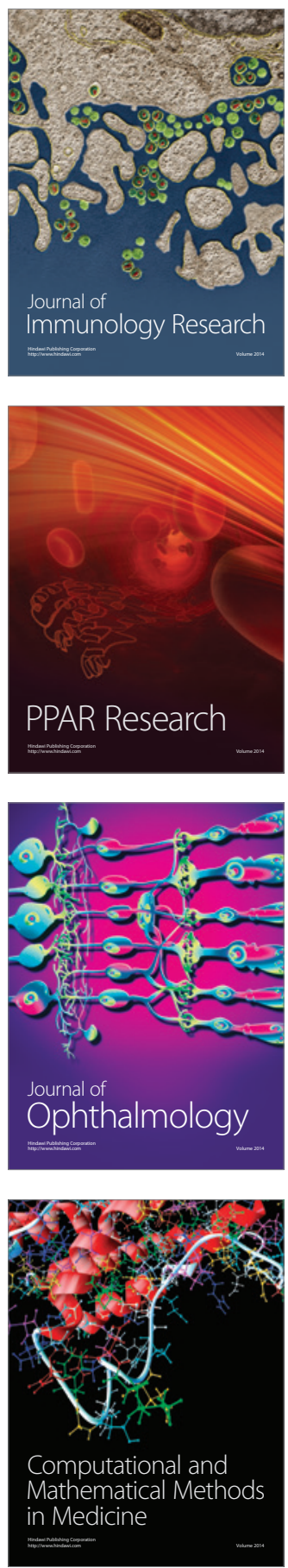

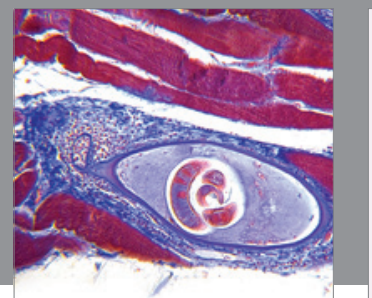

Gastroenterology

Research and Practice
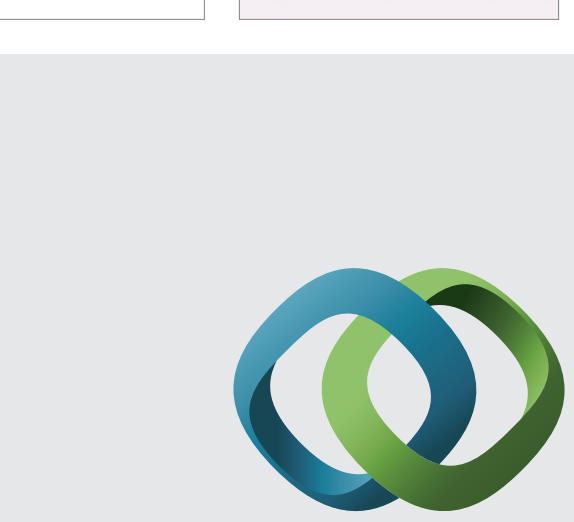

\section{Hindawi}

Submit your manuscripts at

http://www.hindawi.com
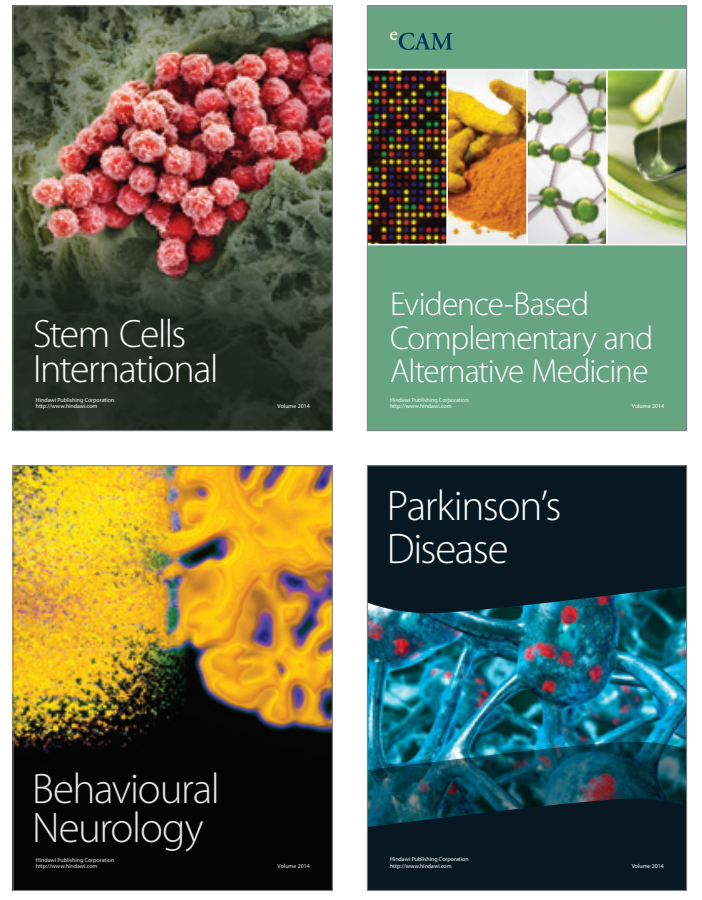
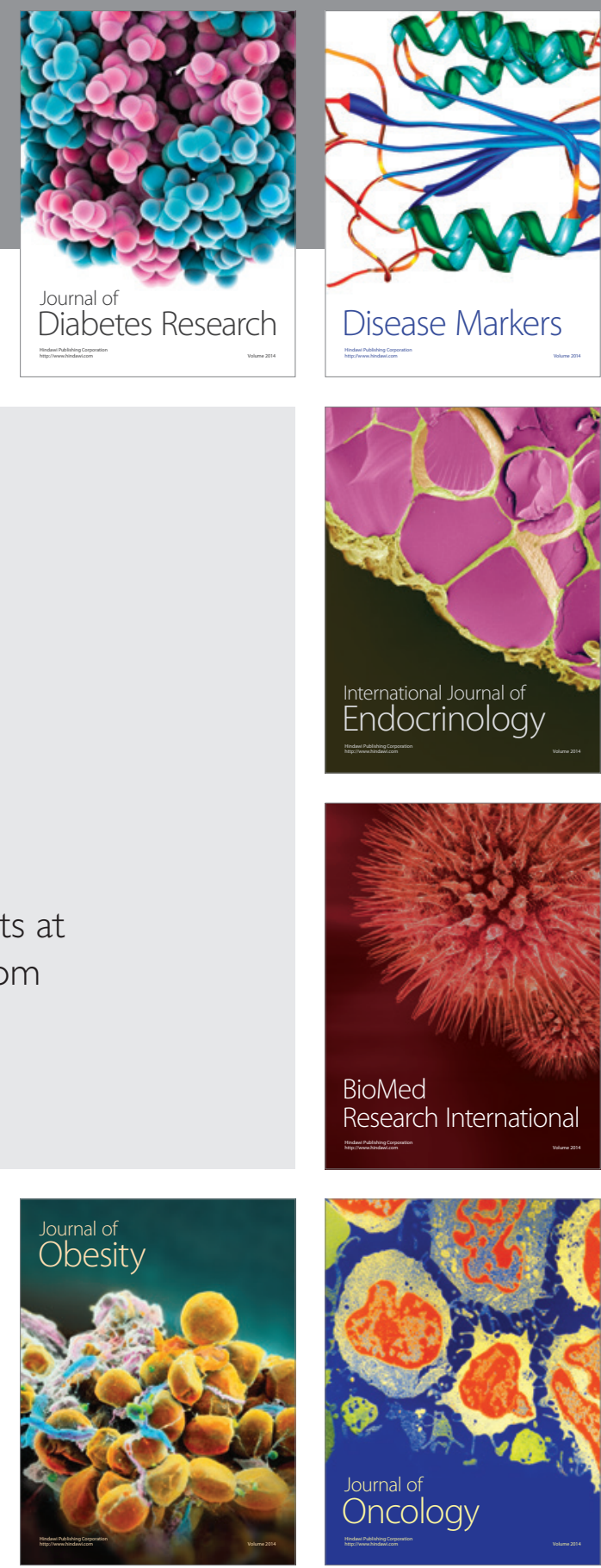

Disease Markers
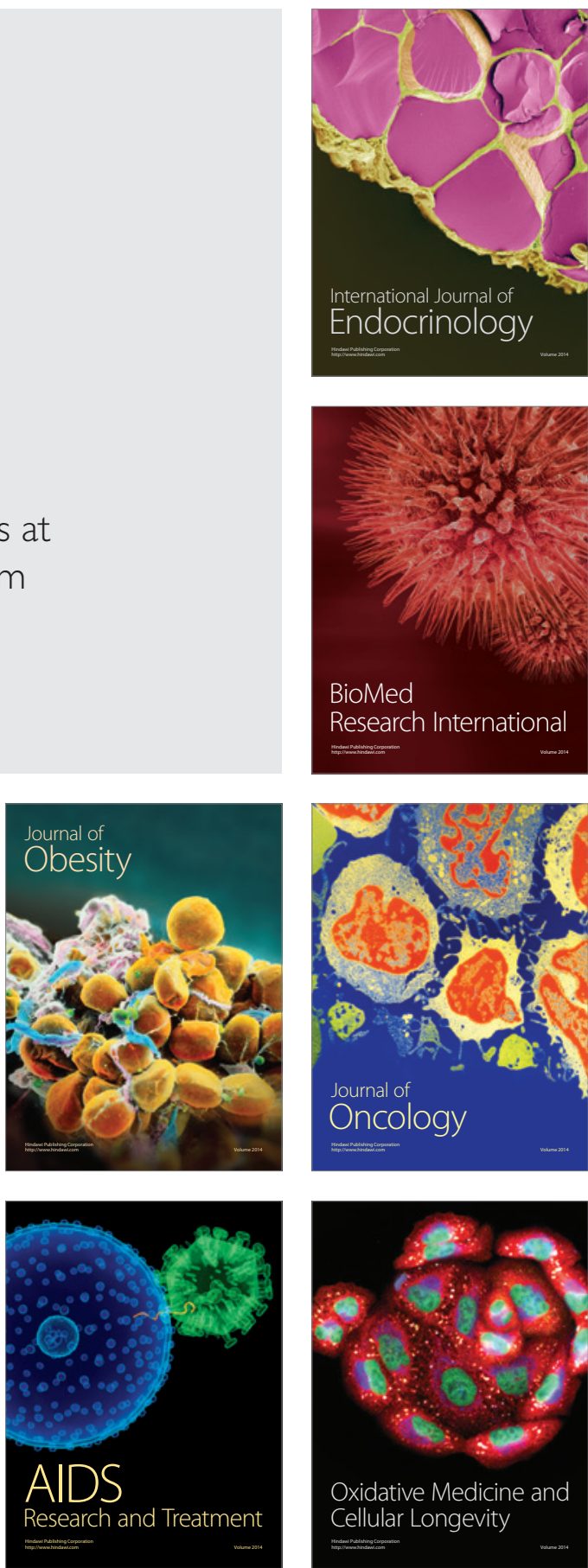